\title{
Grain Growth Predictions in Microalloyed Steels
}

\author{
P. A. MANOHAR, D. P. DUNNE, T. CHANDRA and C. R. KILLMORE'1)
}

Department of Materials Engineering, University of Wollongong, Northfields Avenue, Wollongong, NSW-2522, Australia. 1) BHP Steel - Slab and Plate Products Division, Port Kembla Steel Works, NSW, Australia. E-mail: pm65@uow·edu·au

(Received on June 14, 1995; accepted in final form on September 25, 1995)

\begin{abstract}
Empirical models for grain growth predictions are briefly reviewed. It is demonstrated that such models are inadequate for quantitative prediction of austenite grain growth during reheating of as-cast microstructures in microalloyed steels. This inadequacy is mainly attributable to the inability of empirical models to account for abnormal grain growth. Basic principles of grain growth are therefore revisited in an attempt to develop a mathematical model which can account for abnormal grain growth. Such a model has been developed for $\mathrm{Ti}: \mathrm{N}$ balanced microalloyed steels and is presented here. It is shown that quantitative predictions of austenite grain growth generated from this model fit well with experimental grain growth data obtained during reheating of as-cast slabs of $\mathrm{Ti}, \mathrm{Ti}+\mathrm{Nb}$ as well as $\mathrm{Ti}+\mathrm{Nb}+\mathrm{Mo}$ containing microalloyed steels.
\end{abstract}

KEY WORDS: microalloyed steels; normal grain growth; modelling; particle coarsening; abnormal grain growth.

\section{Introduction}

Beck et al. ${ }^{1)}$ showed that experimentally determined values of grain sizes during normal grain growth under isothermal annealing conditions fitted a power relation such as:

$$
D^{n}-D_{0}^{n}=C \cdot t
$$

where $D$ is the final grain diameter, $D_{0}$ is the initial grain diameter, $t$ is the annealing time and $n$ and $C$ are constants which depend on alloy composition and annealing temperature but are independent of the grain size.

Sellars et al. $^{2)}$ analysed previously published grain growth data on low carbon-manganese steels and arrived at the following general expression for evaluating the constant $C$ in Eq. (1):

$$
d^{n}-d_{0}^{n}=\left[A \cdot \exp \left(-Q_{\mathrm{gg}} / R T\right)\right] \cdot t
$$

Where $n$ and $A$ are constants which depend on material composition and processing conditions, $Q_{\mathrm{gg}}$ is the activation energy for grain growth, $R$ is the universal gas constant and $T$ is the temperature in degrees absolute.

Majority of the current available empirical models which describe grain growth behaviour of austenite are based on Eq. (2) and are briefly reviewed in the following section.

\section{Empirical Models}

Mathematical models describing isothermal grain growth of statically or metadynamically recrystallized austenite in C-Mn, C-Mn-V, C-Mn-Ti and C-Mn-Nb steels are summarized in Table $\mathbf{1 .}$
Another empirical approach has been presented by Yoshie et $a l^{6)}$ and Nishizawa ${ }^{7)}$ to predict grain growth of austenite in as-cast C-Mn steel. Their model can be represented as follows:

$$
d \gamma^{2}-d \gamma_{0}^{2}=k_{2} \cdot t
$$

where, $k_{2}=\sigma \cdot V \cdot D_{\mathrm{gb}} / \lambda \cdot R_{\mathrm{g}} \cdot T$ and

$$
D_{\mathrm{gb}}=D_{\mathrm{gb}}^{\circ} \cdot \exp \left(-Q / R_{\mathrm{g}} T\right),
$$

$d \gamma$ is the final grain diameter $(\mathrm{cm}), d \gamma_{0}$ is the initial grain diameter $(\mathrm{cm}), t$ is the time for grain growths, $\sigma$ is the grain boundary energy $\left(=800 \cdot 10^{-7} \mathrm{~J} / \mathrm{cm}^{2}\right), V$ is the molar volume of austenite $\left(=6.97 \mathrm{~cm}^{3} / \mathrm{mol}\right), D_{\mathrm{gb}}$ is the diffusion constant at grain boundary for iron $\left(\mathrm{cm}^{2} / \mathrm{s}\right)$, $D_{\mathrm{gb}}^{\circ}$ is the diffusion coefficient $\left(=2.0 \mathrm{~cm}^{2} / \mathrm{s}\right), Q$ is the activation energy for diffusion $(=171544 \mathrm{~J} / \mathrm{mol}), R_{\mathrm{g}}$ is the universal gas constant $(=8.31 \mathrm{~J} / \mathrm{mol}-\mathrm{K}), T$ is the absolute temperature $(\mathrm{K})$ and $\lambda$ is the thickness of grain boundary (= lattice parameter of austenite $=3.59 \cdot 10^{-8}$ $\mathrm{cm}$ ).

Assuming a hypothetical but typical value for do of $27 \mu \mathrm{m}, t=1800 \mathrm{sec}$ and solving all above models by substituting $T=1173 \mathrm{~K}\left(900^{\circ} \mathrm{C}\right)$ up to $T=1523 \mathrm{~K}$ $\left(1250^{\circ} \mathrm{C}\right)$ in steps of $50 \mathrm{~K}$, the results obtained are given in Figs. 1, 2 and 3. For comparison, experimental grain growth data for two Ti-steels reported by Feng et al. ${ }^{8)}$ are included in Fig. 2 while data for two Nb-steels reported by Palmiere et al. ${ }^{9)}$ are shown in Fig. 3.

It can be seen from Fig. 1 that the predictions from different models for grain growth of austenite in $\mathrm{C}-\mathrm{Mn}$ steels do not match very well with each other. Also, it is evident from Fig. 2 that predicted sizes for the 076 Ti-steel at temperatures $>1100^{\circ} \mathrm{C}$ are well below the 
ISIJ International, Vol. 36 (1996), No. 2

Table 1. Summary of empirical models describing austenite grain growth.

\begin{tabular}{|c|c|c|c|c|c|c|}
\hline Reference & Steel type & Austenite condition & $n$ & $A$ & $Q_{\mathrm{gg}}$ & Units \\
\hline 2) & $\mathrm{C}-\mathrm{Mn}$ & Statically recrystallized & 10 & $\begin{array}{l}=3.87 \cdot \mathrm{E} 32 \text { for } \\
T>1273 \\
=5.02 \cdot \mathrm{E} 53 \text { for } \\
T<1273\end{array}$ & $\begin{array}{l}=400000 \text { for } \\
T>1273 \\
=914000 \text { for } \\
T<1273\end{array}$ & $\begin{array}{l}\text { g.s. in } \mu \mathrm{m}, Q_{\mathrm{gg}} \text { in } \\
\mathrm{J} / \mathrm{mol}, R \text { in } \mathrm{J} / \mathrm{mol}-\mathrm{K}, \\
t \text { in sec }\end{array}$ \\
\hline 3) & Low C-Mn & Statically recrystallized & 2 & $=4.27 \cdot \mathrm{E} 12$ & $=66600$ & $\begin{array}{l}\text { g.s. in } \mu \mathrm{m}, Q_{\mathrm{gg}} \text { in } \\
\mathrm{kcal} / \mathrm{mol}, R \text { in } \\
\mathrm{kcal} / \mathrm{mol}-\mathrm{K}\end{array}$ \\
\hline 4) & $0.22 \mathrm{C}-0.9 \mathrm{Mn}$ & Statically recrystallized & 2 & $=1.44 \cdot \mathrm{E} 12$ & $=63780$ & $\begin{array}{l}\text { g.s. in } \mu \mathrm{m}, Q_{\mathrm{gg}} \text { in } \\
\mathrm{kcal} / \mathrm{mol}, R \text { in } \\
\mathrm{kcal} / \mathrm{mol}-\mathrm{K}\end{array}$ \\
\hline 5) & $\begin{array}{l}\mathrm{C}-\mathrm{Mn} \text { and } \\
\mathrm{C}-\mathrm{Mn}-\mathrm{V}\end{array}$ & $\begin{array}{l}\text { Statically or } \\
\text { metadynamically } \\
\text { recrystallized }\end{array}$ & 7 & $=1.45 \cdot \mathrm{E} 27$ & $=400000$ & $\begin{array}{l}\text { g.s. in } \mu \mathrm{m}, Q_{\mathrm{gg}} \text { in } \\
\mathrm{J} / \mathrm{mol}, R \text { in } \mathrm{J} / \mathrm{mol}-\mathrm{K}, \\
t \text { in } \sec \end{array}$ \\
\hline 5) & $\mathrm{C}-\mathrm{Mn}-\mathrm{Ti}$ & $\begin{array}{l}\text { Statically or } \\
\text { metadynamically } \\
\text { recrystallized }\end{array}$ & 10 & $=2.6 \cdot \mathrm{E} 28$ & $=437000$ & $\begin{array}{l}\text { g.s. in } \mu \mathrm{m}, Q_{\mathrm{gg}} \text { in } \\
\mathrm{J} / \mathrm{mol}, R \text { in } \mathrm{J} / \mathrm{mol}-\mathrm{K}, \\
t \text { in } \sec \end{array}$ \\
\hline 5) and 23) & $\mathrm{C}-\mathrm{Mn}-\mathrm{Nb}$ & $\begin{array}{l}\text { Statically or } \\
\text { metadynamically } \\
\text { recrystallized }\end{array}$ & 4.5 & $=4.1 \cdot \mathrm{E} 23$ & $=435000$ & $\begin{array}{l}\text { g.s. in } \mu \mathrm{m}, Q_{\mathrm{gg}} \text { in } \\
\mathrm{J} / \mathrm{mol}, R \text { in } \mathrm{J} / \mathrm{mol}-\mathrm{K}, \\
t \text { in sec }\end{array}$ \\
\hline
\end{tabular}

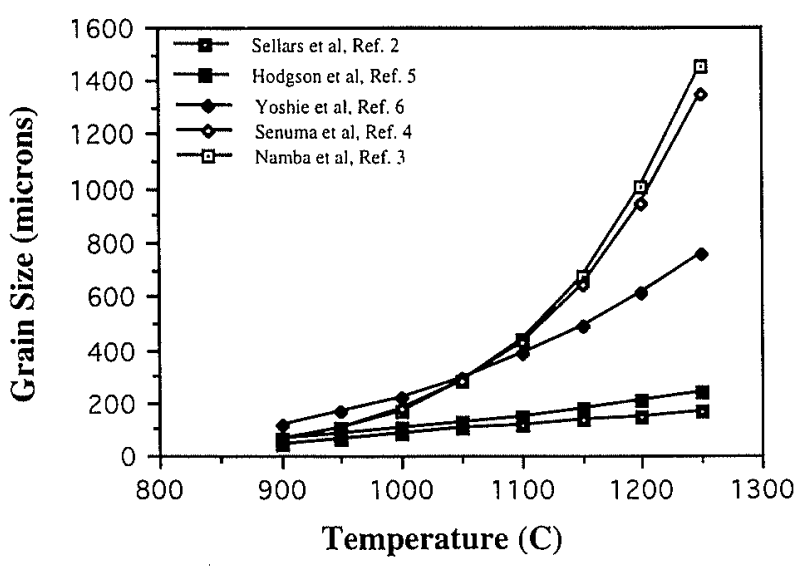

Fig. 1. Predicted austenite grain growth in C-Mn steels.

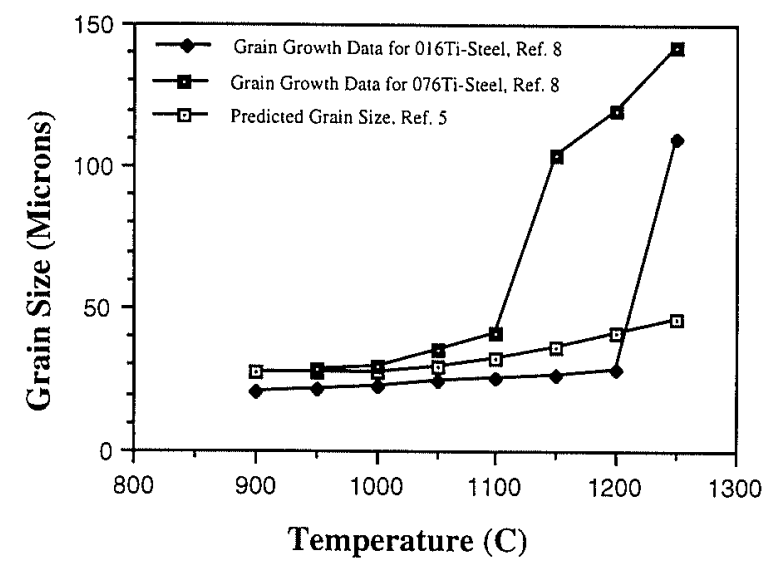

Fig. 2. Comparison of predicted and experimental grain growth behaviour in Ti-microalloyed steels.

experimentally observed values. The model for Ti-steel underestimates the grain sizes due to its inability to account for contribution due to abnormal grain growth at higher temperatures. The 016Ti-steel likewise exhibits a similar trend, but in this case, considerable under-

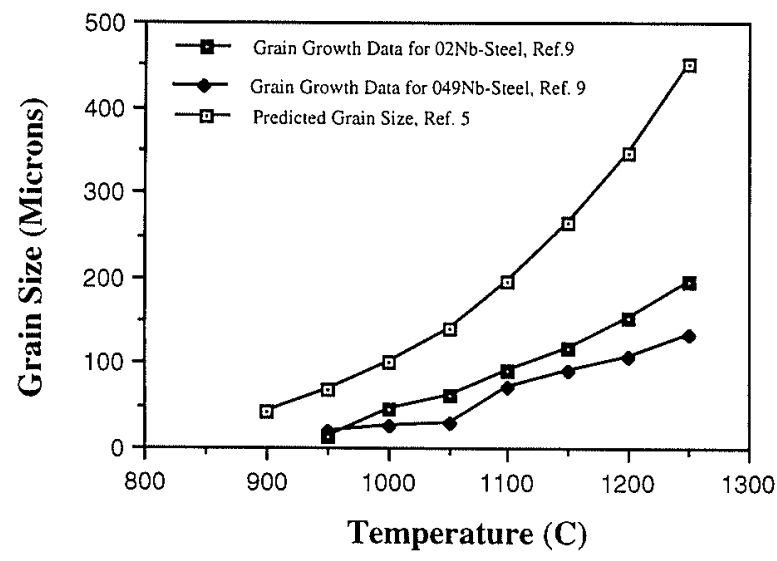

Fig. 3. Comparison of predicted and experimental grain growth behaviour in $\mathrm{Nb}$-microalloyed steels.

estimation is observed at $1250^{\circ} \mathrm{C}$. It can be observed from Fig. 3 that the empirical model for $\mathrm{Nb}$-steels overestimates the grain sizes at all temperatures i.e. $\mathrm{Nb}$-steels exhibit a much lower grain coarsening rate than predicted. This is probably due to the inability of the model to fully account for the retarding influence of second phase particles at lower temperatures and drag effect caused by dissolved $\mathrm{Nb}$ at higher temperatures on the grain growth phenomena in $\mathrm{Nb}$-microalloyed steels. Development of a fundamental model which can account for abnormal grain growth in microalloyed steels is presented in the following section.

\section{Development of Fundamental Model}

\subsection{Background}

A fundamental approach in the theoretical solution of grain growth behaviour, in the presence of second phase particles (such as in microalloyed steels), centers on finding a hypothetical grain radius $R_{\mathrm{cr}}$, such that any grain with radius equal to $R_{\mathrm{cr}}$ will neither grow nor 
shrink. Any grain with radius equal to $R_{\mathrm{cr}}$ is considered to be thermodynamically stable because the driving force for grain growth of such a grain exactly balances the pinning force exerted by the particles on the moving grain boundary. Thus, this is the limiting size to which normal grain growth can proceed. Zener ${ }^{10}$ ) first assigned a quantitative value for $R_{\mathrm{cr}}$ as given below:

$$
R_{\mathrm{cr}}=4 r / 3 f \text {. }
$$

The general form of this equation can be represented as follows:

$$
R_{\mathrm{cr}}=A \cdot r / f
$$

where $A$ is a constant, $r$ is the mean particle radius, $f$ is the volume fraction of particles.

Hillert $^{11}$ has proposed two limits for the constant $A$ in the above equation. For the lower limit, $A=4 / 9(0.44)$, and for this condition normal grain growth would cease. Abnormal grain growth can begin at this stage and it can continue until the upper limit for $A$ is reached, which is equal to $A=2 / 3(0.67)$. At this stage, if all of the grains have a radius $R=R_{\mathrm{cr}}=2 r / 3 f$, then even the abnormal grain growth also has to cease and the entire microstructure is in equilibrium. However, in principle, it is possible to imagine that there exists at least one grain whose radius $R$ is $>R_{\mathrm{cr}}$. In such a case, abnormal grain could continue further, until in the limit, the microstructure consists of a single crystal.

Gladman $^{12)}$ utilized the above formula in a different way and arrived at the criterion for abnormal grain growth. He proposed that abnormal grain growth in the presence of second phase particles will begin when particles coarsen due to coalescence. When particle size reaches a certain critical value, some grains become "unpinned" from such critical sized second phase particles and can grow further. The critical grain radius when unpinning occurs, is as follows:

$$
R=[\pi(1 / 4-1 / 3 Z)] \cdot r / f
$$

where, $Z$ is the ratio of radii of growing grains to matrix grains. Gladman's theory suggests that grain growth inhibition occurs when the value of $Z$ is less than or equal to $4 / 3$. On the other hand, the criterion for grain coarsening becomes unsatisfactory when the value of $Z$ is inordinately large. Gladman found that $Z$ values between 1.41 and 2 give excellent agreement with experimental results. Thus, the value of the constant $A$ could be between 0.05 to 0.26 according to Gladman.

Hannerz and kazinczy ${ }^{13)}$ have chosen $Z=1.7$ based on Hillert's theory. Substituting $Z=1.7$ in the above equation, we get $A=0.17$.

$$
\text { i.e., } \quad R=0.17 \cdot r / f=D / 2 \quad \therefore D=0.34 \cdot r / f
$$

where, $D$ is the critical grain diameter.

Solution of Eq. (3) thus enables the calculation of stable austenite grain size under any combination of volume fraction and particle radius of the precipitates. The dissolution and coarsening of the microalloy precipitates therefore have a pivotal role in deciding the stable austenite grain size. The methodology used to estimate these two parameters is described in the following sections.

\subsection{Prediction of TiN Solubility}

Choice of the equation describing solubility of TiN in austenite is very important. In the current work, we have utilised the TiN solubility product equation given by Matsuda and Okumura. ${ }^{14)}$ Our choice of this equation is explained in detail in discussion section.

$$
\begin{aligned}
& \log [\mathrm{Ti}][\mathrm{N}]=0.322-8000 / T \\
\therefore & {[\mathrm{Ti}][\mathrm{N}]=\log ^{-1}\{0.322-8000 / T\} . }
\end{aligned}
$$

Multiplying both sides by $[\mathrm{Ti}] /[\mathrm{N}]$ :

$$
[\mathrm{Ti}]^{2}=\left[\log ^{-1}\{0.322-8000 / T\}\right] \cdot[\mathrm{Ti}] /[\mathrm{N}] \text {. }
$$

It is assumed that the formation as well as dissolution of TiN precipitates proceeds such that stoichiometric relation of $\mathrm{Ti}: \mathrm{N}\left[=3.42^{8)}\right]$ is maintained whenever the overall $\mathrm{Ti}: \mathrm{N}$ ratio in the given composition of steel is close to the stoichiometric ratio of 3.42 . Therefore, substituting $[\mathrm{Ti}] /[\mathrm{N}]=3.42$ in the above equation:

$$
[\mathrm{Ti}]^{2}=\left[\log ^{-1}\{0.322-8000 / T\}\right] \cdot 3.42 \text {. }
$$

Solution of this equation for different values of $T$ yields the corresponding values of [Ti], which is the percent $\mathrm{Ti}$ in solution in austenite $\left(C^{\mathrm{s}}\right)$. The amount of $\mathrm{Ti}$ out of solution i.e., in precipitate form $\left(C^{\mathrm{p}}\right)$ can now be calculated as $=$ Total $\mathrm{Ti}-C^{\mathrm{s}}$. Total $\mathrm{Ti}$ in this case is $=0.014 \%$. Results of these calculations are presented in Table 2.

\subsection{Calculation of Volume Fraction of Precipitates}

Volume ' $V$ ' of a given mass ' $m$ ' of a material can be given as:

$$
V=m \cdot N a \cdot V u / N u \cdot A r,
$$

where, $N a$ is the Avogadro's number $\left(=6.0222 \cdot 10^{23}\right.$ atoms $/ \mathrm{mol}), V u$ is the volume of one unit cell of the material $\left\{=\left(4.246 \cdot 10^{-8}\right)^{3} \mathrm{~cm}^{316)}\right.$ for TiN and $=(3.59$. $\left.10^{-8}\right)^{3} \mathrm{~cm}^{319}$ for austenite $\}, N u$ is the number of atoms per unit cell of the material ( $=4$ for $\mathrm{TiN}$ and austenite) and $A r$ is the atomic weight of the material ( $=61.91 \mathrm{gms}$ for TiN and $=55.9 \mathrm{gms}$ for austenite). Substituting appropriate numerical values in the above equation,

$$
\begin{aligned}
V_{\mathrm{TiN}} & =0.19 \cdot m_{\mathrm{TiN}} \quad \text { and } \\
V_{\mathrm{Fe}} & =0.13 \cdot m_{\mathrm{Fe}} \\
m_{\mathrm{TiN}} & =m_{\mathrm{Ti}}+m_{\mathrm{N}}=m_{\mathrm{Ti}}+\left(m_{\mathrm{Ti}} / 3.42\right)=1.29 \cdot m_{\mathrm{Ti}}
\end{aligned}
$$

Table 2. Predicted partitioning of $\mathrm{Ti}$ in dissolved and precipitated forms at temperatures of interest.

\begin{tabular}{ccc}
\hline Temperature (K) & $\begin{array}{c}{[\mathrm{Ti}]=C^{\mathrm{s}}=\text { Predicted }} \\
\% \mathrm{Ti} \text { in solution } \\
\text { in austenite }\end{array}$ & $\begin{array}{c}C^{\mathbf{p}}=\text { Predicted } \% \mathrm{Ti} \\
\text { in ppt form } \\
=0.014-C^{\mathbf{s}}\end{array}$ \\
\hline 1173 & 0.00104 & 0.01296 \\
1223 & 0.00144 & 0.01256 \\
1273 & 0.00193 & 0.01207 \\
1323 & 0.00254 & 0.01146 \\
1373 & 0.00327 & 0.01073 \\
1423 & 0.00414 & 0.00986 \\
1473 & 0.00516 & 0.00884 \\
1523 & 0.00633 & 0.00767 \\
\hline
\end{tabular}




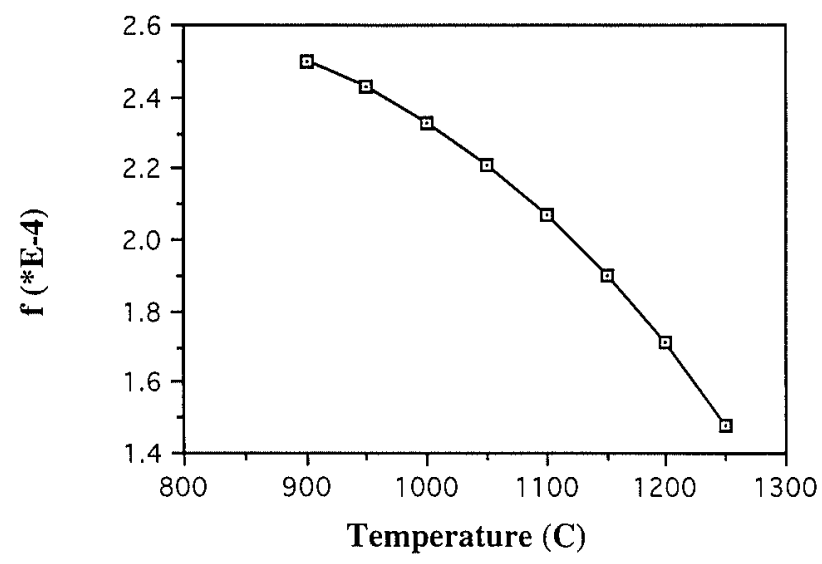

Fig. 4. Predicted volume fraction of precipitates at temperatures of interest.

$$
\begin{aligned}
& m_{\mathrm{Fe}}=1-m_{\mathrm{TiN}} ; \quad \text { and } \\
& m_{\mathrm{Ti}}=C^{\mathrm{p}} / 100 .
\end{aligned}
$$

Volume fraction of precipitates can now be calculated from:

$$
f=V_{\mathrm{TiN}} /\left(V_{\mathrm{TiN}}+V_{\mathrm{Fe}}\right) .
$$

For different values of $T$ we can thus calculate corresponding volume fractions of precipitates as given in Fig. 4.

\subsection{Particle Coarsening}

Lifshitz and Slyozov ${ }^{17)}$ have outline principles of second phase particle coarsening kinetics. The growth process (which follows after the nucleation stage) is considered to begin when the grains (of second phase) have reached appreciable size and the degree of supersaturation of the matrix has become very slight. In this situation, coalescence starts i.e. growth of larger grains by incorporation of smaller ones begins. This theory predicts particle grain growth through the equation as given below:

$$
r^{3}-r_{0}^{3}=\left[8 \cdot \sigma \cdot V \cdot D \cdot t \cdot C^{\mathrm{s}}\right] /[9 \cdot R \cdot T]
$$

where $r$ is the final particle radius (cm), $r_{0}$ is the initial particle radius $(\mathrm{cm}), \sigma$ is the interfacial energy (= grain boundary energy $\left.=800 \cdot 10^{-7} \mathrm{~J} / \mathrm{cm}^{2} 13,15\right)$ ), $V$ is the molar volume of TiN ( $\left.=11.53 \mathrm{~cm}^{3} / \mathrm{mol}\right), D$ is the diffusivity of solute in matrix ( $=\mathrm{Ti}$ in austenite in this case, $\mathrm{cm}^{2} / \mathrm{s}$ ), $t$ is the time for particle coarsening (s), $C^{\mathrm{s}}$ is the concentration of the saturated solution (Table 2), $R$ is the universal gas constant $(=8.31 \mathrm{~J} / \mathrm{mol}-\mathrm{K})$ and $T$ absolute temperature (K).

Diffusivity of $\mathrm{Ti}$ in austenite ${ }^{18)}$ is given as:

$$
D_{\mathrm{Ti}}=0.15 \cdot \exp (-250000 / R T) \mathrm{cm}^{2} / \mathrm{s} \text {. }
$$

Titanium diffusivities in austenite are given in Table $\mathbf{3}$, for selected temperatures.

Considering initial mean particle radius, $r_{0}=13.5$. $10^{-7} \mathrm{~cm},{ }^{8)} t=1800 \mathrm{~s}$ and substituting appropriate numerical values in Eq. (4), we can estimate particle coarsening at different temperatures as given in Fig. 5.

\subsection{Calculation of Predicted Grain Size}

The substitution of the data presented in Fig. 4
Table 3. Diffusivity of $\mathrm{Ti}$ in austenite at temperatures of interest.

\begin{tabular}{cc}
\hline Temperature $(\mathrm{K})$ & $D_{\mathrm{Ti}} \cdot 10^{-12} \mathrm{~cm}^{2} / \mathrm{s}$ \\
\hline 1173 & 1.0905 \\
1223 & 3.1117 \\
1273 & 8.1772 \\
1323 & 19.975 \\
1373 & 45.722 \\
1423 & 98.739 \\
1473 & 202.37 \\
1523 & 395.69 \\
\hline
\end{tabular}

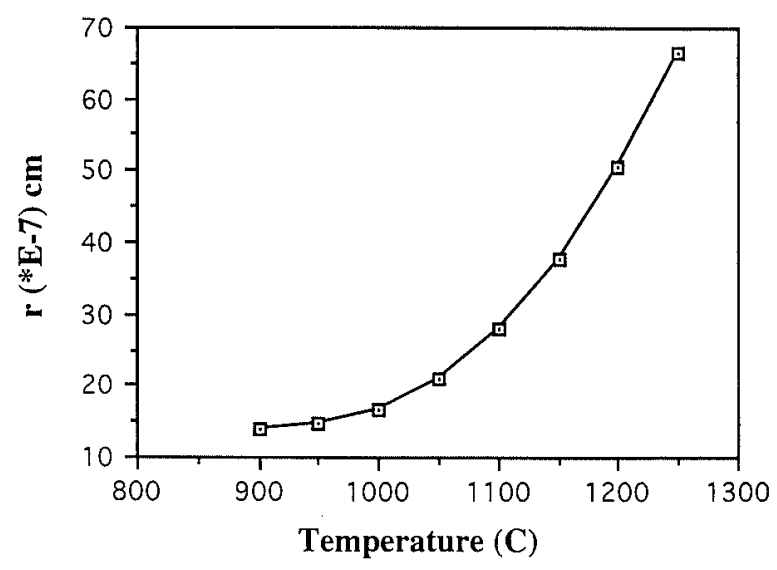

Fig. 5. Predicted particle coarsening with respect to temperature at $t=1800 \mathrm{sec}$.

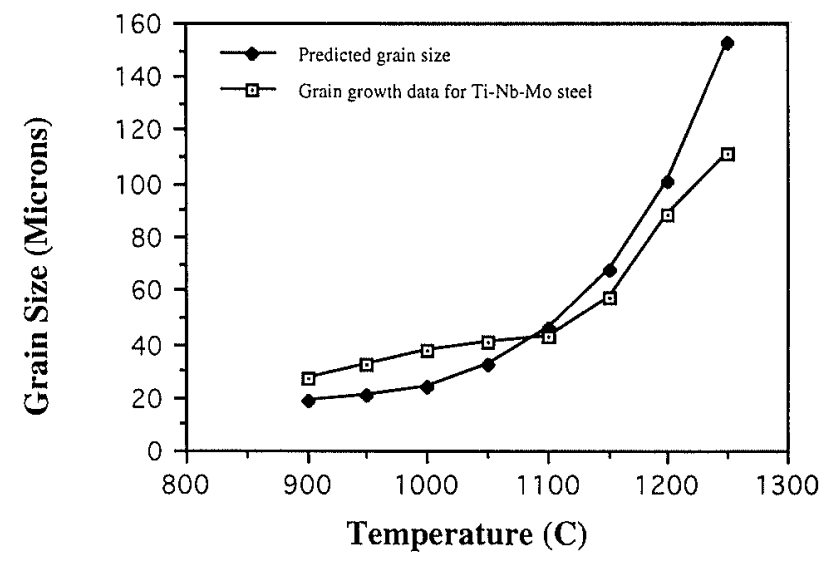

Fig. 6. Comparison of predicted and experimental grain growth behaviour in $\mathrm{Ti}+\mathrm{Nb}+$ Mo-microalloyed steel.

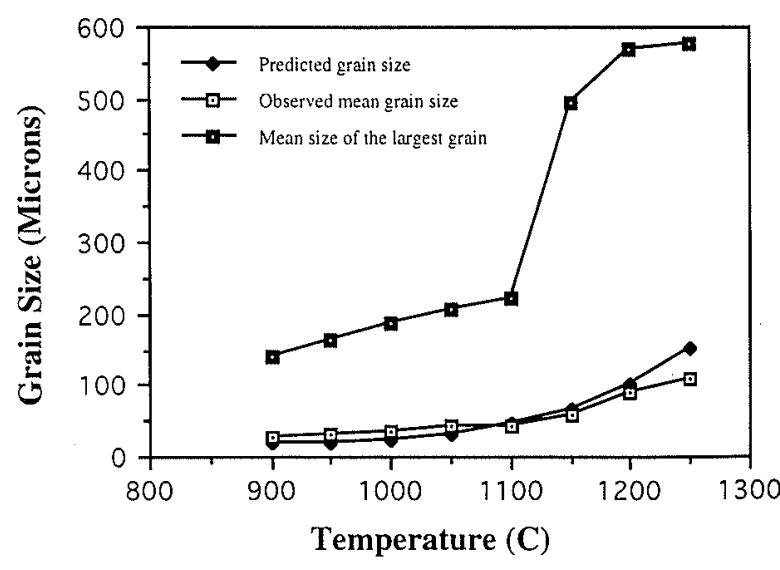

Fig. 7. Size of the largest grain, mean grain size and predicted grain growth for $\mathrm{Ti}+\mathrm{Nb}+\mathrm{Mo}$-microalloyed steel at $t=1800 \mathrm{sec}$ 


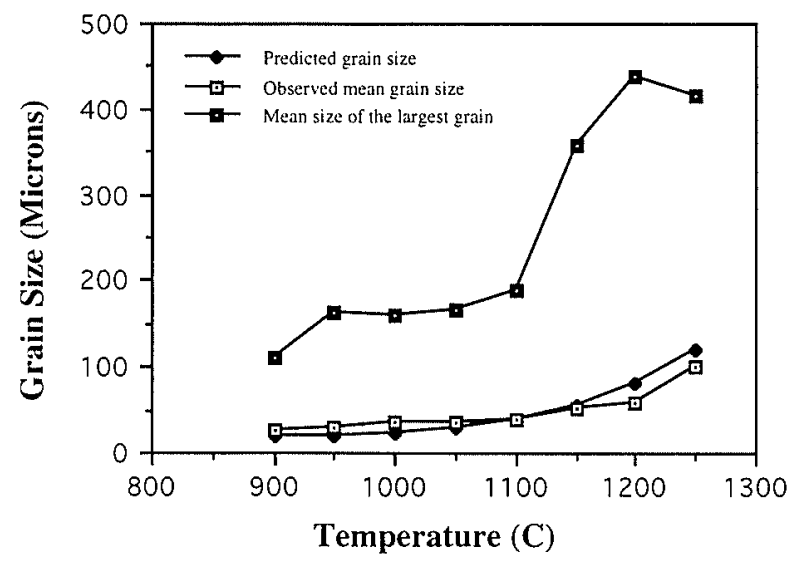

Fig. 8. Size of the largest grain, mean grain size and predicted grain growth for $\mathrm{Ti}+\mathrm{Nb}+$ Mo-microalloyed steel at $t=900 \mathrm{sec}$

(predicted ' $f$ ' values) and Fig. 5 (predicted ' $r$ ' values) in Eq. (3) allows prediction of stable austenite grain size at different temperatures. Results of these calculations are presented in Figs. 6, 7 and 8.

\section{Experimental Procedure}

The microalloyed steel investigated had the following composition: $0.07 \mathrm{C}, 1.08 \mathrm{Mn}, 0.004 \mathrm{~S}, 0.09 \mathrm{Si}, 0.19 \mathrm{Mo}$, $0.033 \mathrm{~A} 1,0.04 \mathrm{Nb}, 0.014 \mathrm{Ti}, 0.0036 \mathrm{~N}$. Cubic samples $(10 \cdot 10 \cdot 10 \mathrm{~mm})$ cut from continuously cast slab of this steel were heated at temperatures between 900 to $1250^{\circ} \mathrm{C}$ in steps of $50^{\circ} \mathrm{C}$ for a period of 900 and $1800 \mathrm{~s}$. The samples were heated in an argon atmosphere and quenched immediately in water after the specified heat treatments were carried out. A thermocouple was inserted into the sample to ensure the correct austenitizing temperature was maintained during each reheating. Quenched samples were sectioned and prepared for metallographic examination. The samples were etched in saturated aqueous picric acid solution containing 10-15 drops of concentrated $\mathrm{HCl}$ and 10-12 drops of detergent (Teepol). Etching was carried out at $60-70^{\circ} \mathrm{C}$ for times ranging from 3 to $14 \mathrm{~min}$ to adequately reveal prior austenite grain size. Some of the samples (particularly those samples with austenitization temperature $>1100^{\circ} \mathrm{C}$ ) were tempered at $500^{\circ} \mathrm{C}$ for $2-3 \mathrm{~h}^{20)}$ to improve the response of the grain boundaries to etching. The mean grain size was measured using quantitative metallographic technique (circle intercept method) according to ASTM E 112, ${ }^{21)}$ ensuring that at least 600 grain intersections were counted for each of the samples. Size of the largest grain in a given field of observation was recorded and arithmatic mean of this data was used to determine the mean size of the largest grain in every sample.

Results of the grain size measurements are presented in Figs. 6, 7 and 8. Calculations based on this fundamental approach were also carried out to predict grain growth behavior of $\mathrm{Ti}$ and $\mathrm{Ti}+\mathrm{Nb}$ steels studied by Feng et $a l .{ }^{8)}$ These predictions are presented along with their experimental grain growth data of these steels in Figs. 9 and 10.

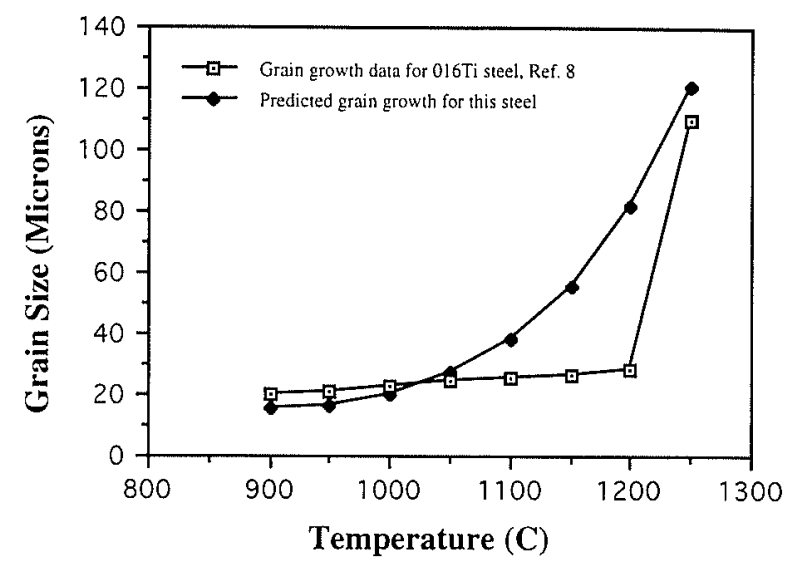

Fig. 9. Comparison of predicted and experimental grain growth behaviour in Ti-microalloyed steel.

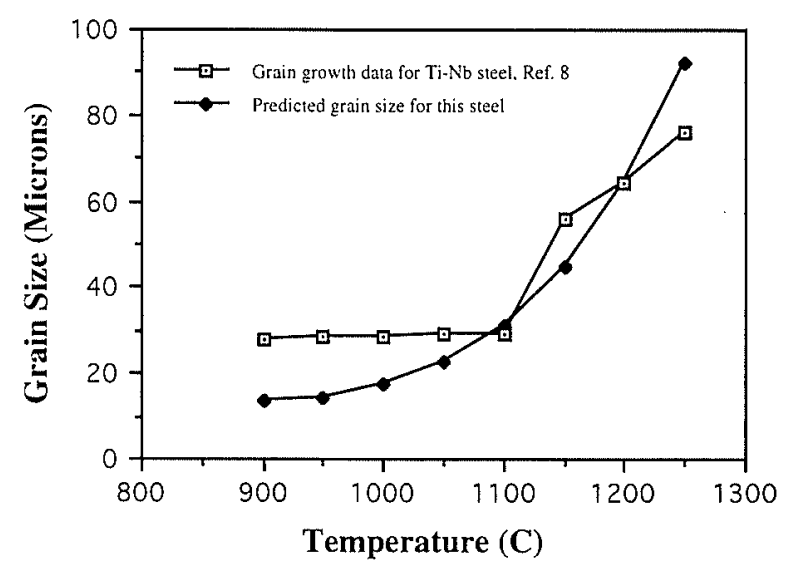

Fig. 10. Comparison of predicted and experimental grain growth behaviour in $\mathrm{Ti}+\mathrm{Nb}$-microalloyed steel.

\section{Discussion}

Data presented in Figs. 7 and 8 indicates three distinct stages in grain growth behaviour of $\mathrm{Ti}-\mathrm{Nb}-\mathrm{Mo}$ microalloyed steel. At lower temperatures $\left(<1100^{\circ} \mathrm{C}\right)$, the observed mean grain size is higher than the predicted grain size. This probably is due to the fact that the original as-cast moicrostructure exhibited a wide range of ferrite grain sizes, with some grains being much larger than the average value. Subsequent re-austenitizing reduced but did not eliminate this variation in grain size. According to Hillert's ${ }^{11)}$ size distribution theory, grains with radius greater than 1.8 times mean grain radius are unstable and should grow abnormally at the expense of the remainder until an even size distribution is achieved. This expected low temperature abnormal grain growth is not observed in this case as indicated by a marginal increase in mean grain size and a lower slope of largest grain size curve for both holding times. This means that abnormal grain growth due to the size difference effect is either insignificant or very sluggish in microalloyed steels at lower temperatures. Grain growth in this temperature region, therefore, can be considered as stable or normal grain growth in the presence of second phase particles.

At intermediate temperatures $\left(1100-1200^{\circ} \mathrm{C}\right)$, the size of the largest grain increases sharply and also the curve for mean grain size exhibits a higher slope for both holding times. The predicted value for grain size is 


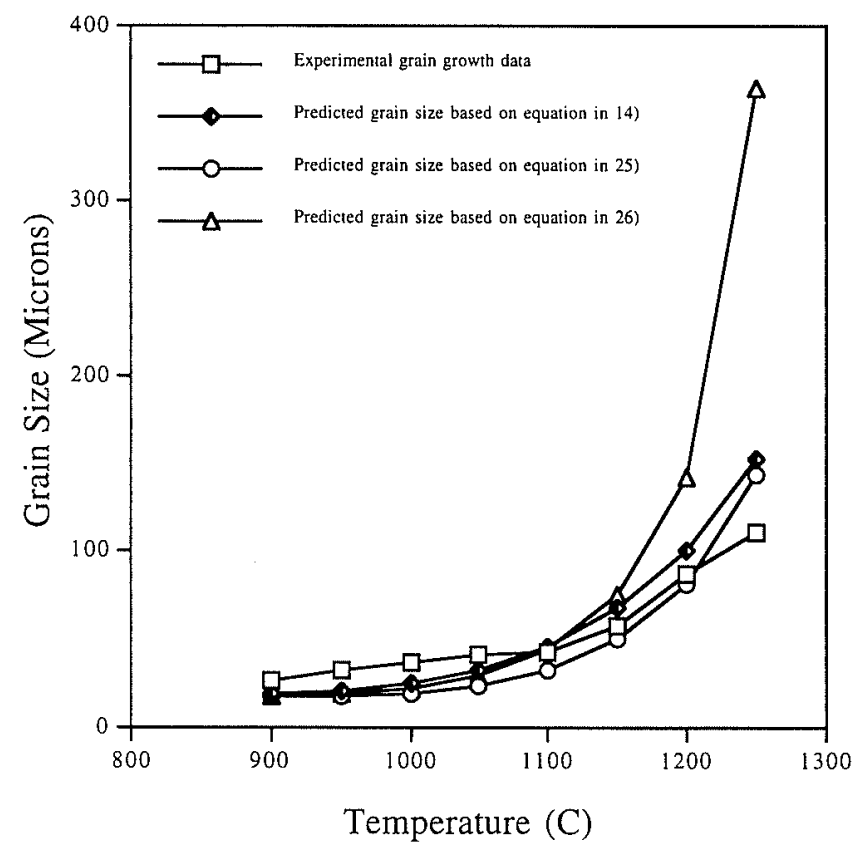

Fig. 11. Effect of choice of TiN solubility product equation on predicted austenite grain growth.

approached very closely in this region. This behaviour is typical of abnormal grain growth as described by Zener $^{10)}$ and Gladman ${ }^{12}$ and is due to progressive particle dissolution and particle coarsening.

At temperatures around $1250^{\circ} \mathrm{C}$, the situation is relatively stabilized as indicated by flattening of the curve for size of the largest grain. Mean grain size drops below the predicted theoretical limit. This means that abnormal grain growth has been reduced, probably due to impingement of growing grains with only minor inhibition for grain growth being offered by either dissolved or coarsened second phase particles at these high temperatures. Grain growth in this temperature region can, therefore, be considered as high temperature normal grain growth.

Thus, the experimentally observed and predicted grain sizes match with a fair degree of accuracy in all 3 stages of grain growth (low temperature normal grain growth, abnormal grain growth and high temperature normal grain growth) in this $\mathrm{Ti}+\mathrm{Nb}+$ Mo microalloyed steel.

Choice of the solubility product equation for TiN precipitates is very important because partitioning of Ti in precipitates and in austenite matrix plays a crucial role in deciding grain growth of microalloyed austenite. Many equations, for example, ${ }^{14,25,26)}$ are available in the literature which describe TiN dissolution in austenite. Effect of choice of these equations on predicted austenite grain growth is presented in Fig. 11. It is clear from Fig. 11 that, the grain growth predictions using equations by Matsuda et al. ${ }^{14)}$ and Kunze ${ }^{25)}$ are closer to the experimental data. In particular, predictions based on equation from ${ }^{14)}$ are found to be better at lower temperatures as compared to the predictions based on equation from. ${ }^{25)}$

It is, however, necessary to understand the framework within which the suggested model would apply. Derivation and application of Zener's formula involved certain assumptions/limitations as outlined below:

(1) The equation does not account for the influence of the initial condition of the microstructure (e.g. as-cast, rolled, normalised etc.) and of initial or starting grain size on the final grain size that would be developed during the process of grain growth.

(2) It is assumed that the precipitate dissolution process reaches steady state during heating and isothermal soaking, allowing the use of thermodynamic equations describing the precipitate dissolution process.

(3) It is assumed that precipitate particles are spherical in shape and are randomly distributed on the surface of the grain boundary. The influence of any particles present on the grain edges or grain corners is not considered.

(4) It is assumed that all particles are equal in size.

(5) $R$ indicates a theoretical value for grain size at the onset of abnormal grain growth and does not indicate the grain size distribution or the mean grain size in actual samples.

In addition to the above, further qualifying assumptions were made in the present work as outlined below:

(1) Mathematical models for predicting particle coarsening kinetics and volume fraction predictions do not account for synergistic effects of other alloying elements such as Mn, Mo, Si etc.

(2) The model is applicable to those steels where overall $\mathrm{Ti}: \mathrm{N}$ ratio in steel composition is equal to or less than the stoichiometric ratio of 3.42. In other words, this means that all of the available Ti forms TiN particles and formation of low temperature dissolving precipitates such as $\mathrm{TiC}, \mathrm{Ti}(\mathrm{C}, \mathrm{S})$ etc. is avoided.

(3) The starting condition of the steel is in the form of continuously cast slab.

(4) Fine TiN precipitates are assumed to control the grain growth behaviour at all temperatures and the influence of possible 'mixed' precipitates such as $\mathrm{Ti}, \mathrm{Nb}(\mathrm{C}, \mathrm{N})$ on grain growth behaviour is not accounted for in the present mathematical model.

Notwithstanding these limitations, a number of authors ${ }^{6,13,15,22)}$ have utilized basic principles developed by Zener and Gladman for quantitative predictions of austenite grain growth in microalloyed steels. More recently, Gladman ${ }^{24)}$ has used a similar approach in effectively estimating austenite grain growth in $\mathrm{Al}$ containing steels in the temperature range of 850 up to $1000^{\circ} \mathrm{C}$. Results of the current work also strongly support the applicability of these fundamental principles to successfully explain the grain growth behaviour of modern steels in spite of the limitations discussed above.

\section{Conclusions}

(1) Abnormal grain growth due to initial (reheated) austenite grain size differences appears to be insignificant in microalloyed steels.

(2) A plot of size of the largest grain $v s$. temperature provides an effective and sensitive method for detecting the onset and termination of abnormal grain growth in microalloyed steels.

(3) Some empirical models are effective in predicting 
grain coarsening behaviour of microalloyed steels at lower temperatures. However, these models underestimate grain coarsening behaviour of Ti-steels and overestimate grain coarsening behaviour of $\mathrm{Nb}$-steels at higher temperatures.

(4) Grain coarsening behaviour of $\mathrm{Ti}+\mathrm{Nb}+\mathrm{Mo}$ steel observed in the current work can be successfully explained by the application of the fundamental model developed in the current work.

(5) Grain growth predictions for $\mathrm{Ti}$ and $\mathrm{Ti}+\mathrm{Nb}$ steels compare well with the experimental grain growth data for these steels.

(6) The fundamental model successfully accounts for abnormal grain growth in $\mathrm{Ti} / \mathrm{Ti}+\mathrm{Nb} / \mathrm{Ti}+\mathrm{Nb}+\mathrm{Mo}$ containing microalloyed steels on reheating the as-cast slabs, when the overall $\mathrm{Ti}: \mathrm{N}$ ratio for the steel composition is close to the stoichiometric value of 3.42 .

\section{REFERENCES}

1) P. A. Beck, J. C. Kremer, L. J. Demer and M. L. Holzworth: Trans. AIME, 175 (1948), 372.

2) C. M. Sellars and J. A. Whiteman: Metal Sci. J., 13 (1979), 187.

3) S. Namba, M. Kitamura, M. Shimada, M. Katsumata, T. Inoue, H. Imamura, Y. Maeda and S. Hattori: ISIJ Int., 32 (1992), 377.

4) T. Senuma and H. Yada: Annealing Processes-Recovery, Recrystallization and Grain Growth, 7th Riso Int. Symp. on Metallurgy and Materials Science, ed. by N. Hansen et al., Riso, Roskilde, Denmark, (1986), 547.

5) P. D. Hodgson and R. K. Gibbs: ISIJ Int., 32 (1992), 1329.

6) A. Yoshie, M. Fujioka, Y. Watanabe, K. Nishioka and H. Morikawa: ISIJ Int., 32 (1992), 395.
7) T. Nishizawa: Tetsu-to-Hagané, 70 (1984), 1984.

8) B. Feng, T. Chandra and D. P. Dunne: Mater. Forum, 13 (1989), 139.

9) E. J. Palmiere, C. I. Garcia and A. J. DeArdo: Metall. Trans. ASM, 25A (1994), 2778.

10) C. Zener: As quoted by C. S. Smith, Trans. AIME, 175 (1948), 15 .

11) M. Hillert: Acta Metall., 13 (1965), 227.

12) T. Gladman and F. B. Pickering: J. Iron Steel Inst., 205 (1967), 653.

13) N. Hannerz and F. Kazinczy: J. Iron Steel Inst, 208 (1970), 475.

14) S. Matsuda and N. Okumura: Trans. Iron Steel Inst. Jpn., 18 (1978), 198.

15) Y. Saito and M. Enomoto: ISIJ Int., 32 (1992), 267.

16) W. B. Pearson: Handbook of Lattice Spacings and Structures of Metals and Alloys, Vol. 2, Pergmon Press, Oxford, England, (1967), 455.

17) I. M. Lifshitz and V. V. Slyozov: J. Phys. Chem. Solids, 19 (1961), 35 .

18) S. Suzuki, G. C. Weatherly and D. C. Houghton: Acta Metall., 35 (1987), 341

19) D. R. Askeland: The Science and Engineering of Materials, Chapman and Hall Publishers, 2nd SI Ed., London, England, (1990), 867.

20) M. J. Godden. L. E. Collins and J. D. Boyd: Proc. of Int. Conf on HSLA Steels, ed. by D. P. Dunne and T. Chandra, Wollongong, Australia, (1984), 114

21) ASTM E: 112, 205-237.

22) W. J. Liu and J. J. Jonas: Proc. of Int. Conf. on Physical Metallurgy of Thermomechanical Processing of Steels and Other Metals, Thermec 88, ed. by I. Tamura, ISIJ, Tokyo, (1988), 90.

23) J. H. Beynon and C. M. Sellars: ISIJ Int., 32 (1992), 359.

24) T. Goldman: Heat Treat. Met., 1994.1 (1994), I1.

25) J. Kunze: Met. Sci., 16 (1982), 11.

26) H. Wada and D. Pehlke: Metall. Trans. B, 16B (1985), 815. 